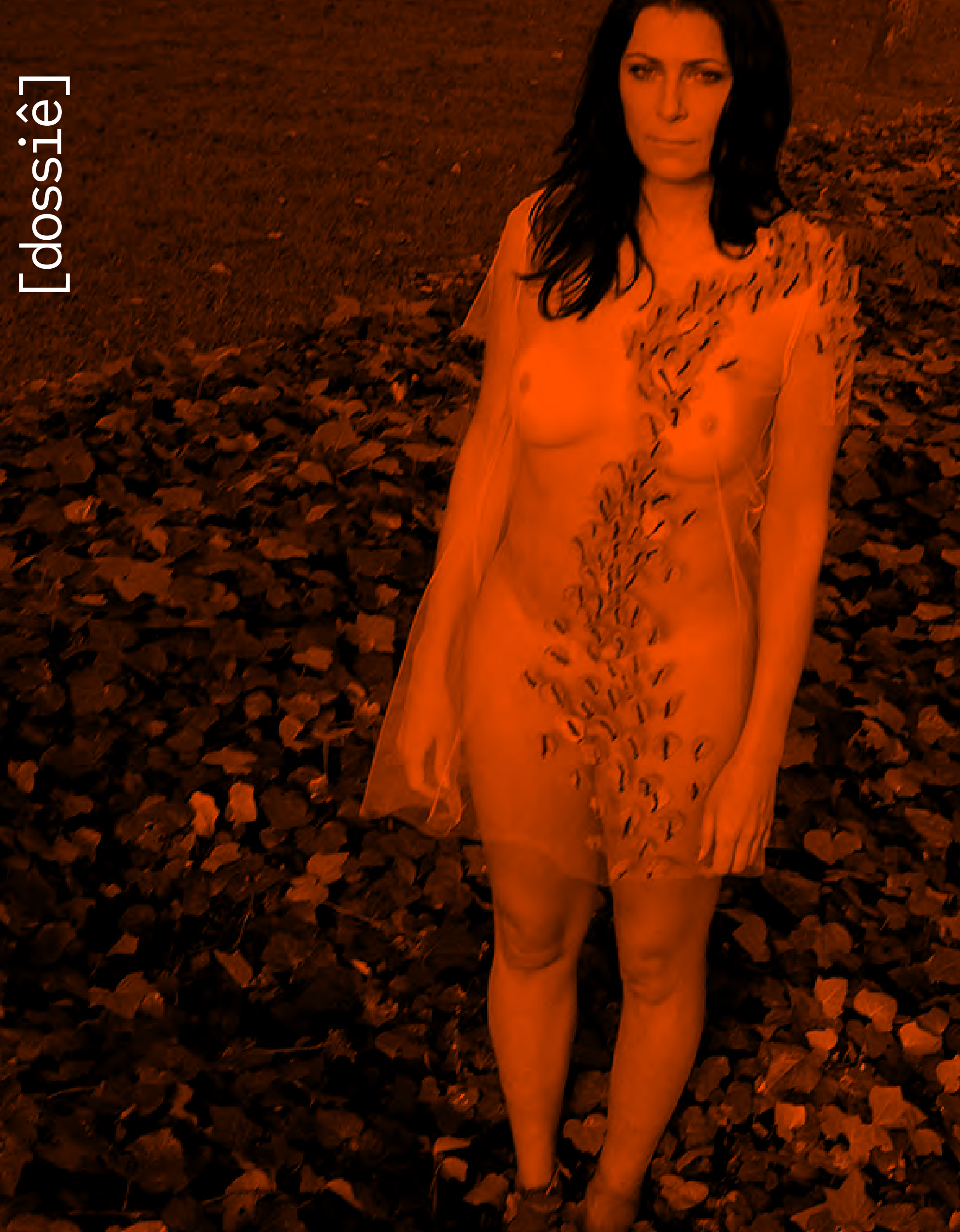




\title{
Moda ética, um novo olhar sobre o novo
}

\section{Ethical fashion, a new look on the new}

\author{
Lilyan Berlim ${ }^{1}$ \\ ORCID: https://orcid.org/0000-0002-2360-3889 \\ Neide Schulte ${ }^{2}$ \\ ORCID: https://orcid.org/0000-0001-5690-5819
}

Em uma sociedade com urgentes desafios socioculturais, políticos e ambientais, a área de moda enfrenta a necessidade de se rever. Permeada de rachaduras, a moda atual se move de forma complexa tentando sair do lugar no qual foi colocada, e celebrada, por um sistema excludente e irresponsável. Por suas rachaduras escorrem rios azuis envenenados por metais pesados usados no tingimento do jeans, terras inférteis pelo emprego incessante de agrotóxicos, lágrimas daqueles que são ignorados e excluídos e sangue dos que perdem a vida nos sweatshops; pela maior rachadura explode lixo em uma quantidade quase impossível de mensurar - centena de milhares de toneladas anuais de roupas, retalhos, fios, linhas, sapatos e bolsas (muitas vezes ainda com etiquetas) se espalham em torno do sul global, para onde as rachaduras apontam. Empacotada em plástico, vendida por meio de ilusões e precificada aos custos do que vaza por suas rachaduras, a moda vem sendo encurralada pela difusão de informações e, também, pela emergência de um sentido humano de engajamento na vida. Assim, em uma área em que a estética sempre imperou, a ética passa a se fazer presente.

Entendendo esse engajamento como cívico, podemos afirmar que nunca a moda viveu sua esfera política com tanta desenvoltura. Há no ar uma insatisfação crônica que desafia marcas, estratégias e modelos de negócios, e que chegou aos estilos de vida, portanto também ao vestir contemporâneo. Fora os movimentos formais por mais ética na área, como aqueles do consumo consciente, o Fashion Revolution e o slow fashion, entre outros

\footnotetext{
${ }^{1}$ Doutora em Ciências Sociais pela Universidade Federal Rural do Rio de Janeiro. Docente da Escola Superior de Propaganda e Marketing (ESPM) no Rio de Janeiro. Pesquisadora do Laboratório de Mudanças Climáticas e Práticas Sustentáveis da ESPM. E-mail: Lilyan.berlim@espm.br. Lattes: http://lattes. cnpq.br/9735162144420242.

2 Doutora em Design pela PUC-Rio. Professora titular da Universidade do Estado de Santa Catarina (Udesc). Coordenadora do Programa EcoModa da Udesc. Diretora de Extensão do Ceart/Udesc. E-mail: neideschulte@gmail.com. Lattes: http://Lattes.cnpq.br/2166230362197561.
} 
que versam sobre a pluralidade cultural e a diversidade, assistimos indivíduos comuns entendendo seu poder de agência nas práticas de compra e de uso e, nesse contexto, exercendo seu poder de consumidor ao elencar o boicote e o buycott como estratégias de crítica social e de transformação.

A dimensão ética e social da agência social se expande para além do ativismo clássico, coletivo, ligado aos sindicatos e outras esferas, e encontra na ação individual as micropolíticas necessárias para mudanças profundas. Assistimos na moda uma interseção da ética com a dimensão estética que assume novos discursos e assinala uma reorganização de todo o campo. Poderíamos, então, entender que está em curso um processo de eticização na moda.

Costumamos usar a ideia de que transatlânticos não dão cavalos de pau, para mudar suas rotas eles fazem grandes e lentas curvas. Essa figura de linguagem serve para entendermos o momento atual de algumas das reconhecidas marcas de moda e da maioria dos grandes varejistas globais (muitos já entenderam que o colapso é eminente se a rota não for alterada); mas ela também nos serve para falarmos de mudança de modelos mentais, ou das construções culturais nas quais fomos formados. A maneira como entendemos a moda e seus mecanismos talvez represente o ponto preciso de mudança, a quebra de paradigmas que fará a grande diferença na rota do transatlântico.

As questões ainda não respondidas e solucionadas são muitas e, talvez, ainda tenhamos que aguardar algum tempo para começarmos a vislumbrar possíveis respostas e soluções colocadas em prática. Esse número da dobra[s] entrega novos olhares sobre essas possíveis respostas.

Como postula Barthes (1979), a moda é um sistema de significados, com códigos imateriais e valores. Lipovetsky (1998) por sua vez diz que, como um sistema, a moda é fundamentalmente caracterizada pela dinâmica das mudanças na qual o desejo pelo novo foi comoditizado. No sistema da moda, a imaterialidade de seus códigos e a importância do glamour, das passarelas, do dinheiro e da mercantilização de roupas e acessórios tramitam nas subjetividades sem deixar espaço para a dimensão da materialidade em si - a materialidade ficou atrelada ao produto oriundo não de recursos naturais, mas de uma determinada marca e seus capitais simbólicos. Nesse sistema, a dimensão humana também é reduzida a aparência e a uma subjetividade identitária excludente, colonizada e mercadológica. Portanto, quando adentramos o vasto e autogerível sistema imaterial da moda atual, percebemos o quão ele é insustentável.

Parece-nos que para encontrar a sustentabilidade na moda seria preciso, primeiramente, reverter o sistema de moda, tal qual o conhecemos, para um que tivesse uma dimensão humana carregada de valores, não excludente e engajada com a materialidade das roupas e dos acessórios. Não excludente porque, como dimensão humana, portanto maior, ela acolheria variadas subjetividades, identidades, culturas, os mais diversos seres humanos e as interações entre eles. Nessa dimensão, tanto quem usa quanto quem faz as roupas estariam presentes; e enquanto engajamento com a materialidade, ela entenderia a materialidade por meio da estética do afeto, do cuidado e do respeito para com a natureza, da qual somos parte e da qual são extraídos todos os recursos para a confecção das roupas. 
Entendemos que essa mudança de paradigma é algo novo, mas que pode levar muito tempo, mas é preciso apostarmos e trabalharmos nessa transformação.

O $32^{\circ}$ número da dObra[s], o segundo elaborado durante uma pandemia global, pode ser definido por diversos termos: como uma aposta no futuro, uma contribuição e um fomento à pesquisa ou ainda um incentivo às boas práticas, mas, antes de tudo, esta edição se ocupa de trilhar um caminho científico crítico e afirmativo sobre a ética na moda. Todas as mudanças em curso são boas e admiráveis; entretanto, ética não é algo que está na superfície das mudanças, mas no fundamento delas - no por que elas são engendradas, e isso não está em lugar algum que não na dimensão do pensamento e da consciência. Portanto, esse primeiro número dedicado à ética na moda traz em si uma chamada às consciências tanto de quem faz quanto de quem usa, gosta e pensa a moda.

Nas últimas décadas, presenciamos o começo de uma reconfiguração do campo do design de moda. Inúmeros movimentos surgiram contestando a insustentabilidade da indústria da moda e elencando soluções ideológicas e práticas para consumidores, gestores e designers. Apareceram variadas marcas de moda que se configuram dentro do escopo da sustentabilidade e da ética, que incorporam diferentes formas econômicas, como economia criativa, circular, compartilhada, solidária e associativa, bem como novas práticas como o DIY (faça você mesmo), o sharing (compartilhamento), o uso de roupas de segunda mão, o upcycling, os tingimentos naturais e o open source design (fonte aberta de design), entre outras. A indústria, juntamente com o mercado, constrói alternativas ligadas à economia circular, novos materiais e posturas socioculturais mais includentes. Os modelos de negócios se reinventaram para acompanhar não apenas um consumidor que surge mais atento e consciente, mas também as demandas geracionais de gestores. Não há dúvida de que o campo se encontra em transformação. Entretanto, ainda há no sistema de moda a sensação de tudo novo de novo, um sentimento que legitima alegarmos que a verdadeira mudança para a sustentabilidade está na transformação do sistema de moda em si, retirando-o do modo uníssono mercadológico no qual se baseia e o abrindo para uma dimensão na qual a energia criativa e humana da moda possa ser a mais importante do sistema.

Ao pensarmos na sustentabilidade na moda, acreditamos em uma transformação que de fato tornasse mais robustas as mudanças em curso, considerando a urgências ambientais, sociais e culturais. Dessa maneira, acreditamos que Li Edelkoort estava correta quando, em 2015, propôs um retorno à roupa, pois o ato de vestir, se redimensionado, pode nos conectar com importância à materialidade, ligada aos processos e às matérias-primas e, também, à dimensão humana que ao longo da cadeia produtiva transforma materiais em roupa e, posteriormente, em mercadoria.

0 vestir contemporâneo evoca, hoje, também um sentido ético que se soma à questão estética. Não usamos mais apenas uma camiseta, na qual estão impressas frases como "Salve o meio ambiente" ou "Adote uma criança", mas vestimos uma camiseta de algodão orgânico ou de algodão de cultivo convencional (cuja insustentabilidade da produção é comprovada), ou uma camiseta comprada de uma marca preta ou indígena, que traz estampas 
que dialogam com as culturas que vêm sendo apagadas ou excluídas. Dessa maneira, estamos nos vestindo com os valores das cadeias produtivas e contribuindo, portanto, para a preservação ambiental e a justiça social, ou, ao contrário, para a degradação social e ambiental e, também, para a afirmação da resistência de culturas outras que a moda (e o sistema em geral) sempre recusou. Assim, tencionam-se a estética e a ética. Nesse território, que aqui poderia ser chamado, por analogia, de tecido, no qual a estética seria o urdume e a ética seria a trama, está uma nova expressão das subjetividades que se relacionam com as questões da sustentabilidade.

São essas novas subjetividades e suas expressões que compoem o repertório de ideias que norteiam esse número 32 voltado para A moda ética, um novo olhar sobre o novo. Tais subjetividades convergem para novos olhares sobre o campo em sua totalidade.

Assim, abrimos este precioso número com uma reflexão legítima sobre o paradoxo fast-slow trazida por Felipe Guimarães e Mirtes Marins de Oliveira. Com a intenção de contribuir para uma revisão dos sistemas produtivos da cadeia têxtil e suas formas organizativas de trabalho, os autores pensam as questões subjetivas e empíricas do fast e do slow na moda problematizando-as com lucidez mediante um sistema econômico imperativo. Em Fast-slow: o paradoxo do cenário têxtil-confecção-moda, Felipe e Mirtes trazem reflexões que descontroem uma visão superficial do paradoxo exposto e despertam questionamentos importantes para uma mudança genuína.

Na sequência entra Construindo um design para a economia verde, um ponto central no contexto da moda. Trazendo-nos uma rica fonte de possibilidades que viabilizam um paradigma econômico mais equânime, coeso e íntegro social e ambientalmente, Gabriela Duarte e Aguinaldo dos Santos falam de um design para a green economy. Como uma contribuição importante para as áreas do design e da economia, são abordados conceitos como economia criativa, economia circular, economia compartilhada, economia colaborativa, economia distribuída e o comércio justo.

Para pensar as interfaces da moda e seus ciclos produtivos com o meio ambiente, Teresa Campos Viana Souza, Rita Aparecida da Conceição Ribeiro, Eliane Ayres e Frederico Campos Viana partem do princípio de que um dos paradigmas dos próximos anos é uma interação respeitosa dos processos produtivos com a natureza. No artigo A sustentabilidade na indústria da moda e o ressurgimento dos corantes naturais: desafios e possibilidades no século XXI, os autores abordam o tingimento natural oferecendo-nos importantes informações sobre seu uso, suas matérias-primas e seus processos, entre outros fatos. No texto, a materialidade e seu desempenho na moda ganha destaque e nos remete à dimensão material da moda, que precisa urgentemente ser revista.

Em seguida, o texto Relações entre moda, sustentabilidade e vida: a "roupa viva" de Flavia Aranha, de Tatiana Massaro, fala sobre tingimentos naturais, tecidos orgânicos e uma cadeia de produção com transparência, em roupas criadas e produzidas pela marca Flávia Aranha, uma das pioneiras em tingimento natural no Brasil. Nesse artigo, conjugam-se elementos essenciais da sustentabildiade na moda e da relação das roupas com a vida. 
Para finalizar, escolhemos o precioso texto de Rogério D’Ávila Ortiz e Christine Greiner Atravessamentos entre moda e arte em busca da sustentabilidade - um experimento com Fernanda Yamamoto. Alinhados com a contemporaneidade e mostrando-se presentes em um novo modelo mental em relação à moda, eles nos presenteiam com parte de uma pesquisa de doutorado que indaga o tempo, o corpo e os movimentos que a moda pode constituir. Libertando o corpo do suporte de produtos comoditizados em um sistema fechado de representações pré-impostas, e questionando novas possibilidades relacionais que poderiam significar um novo sistema de moda, os autores revelam a dimensão humana, viva, criativa, potente e artística da moda.

Este número conta ainda com o artigo Contribuições para a construção do conceito do slow fashion: um novo olhar sobre a possibilidade da leveza sustentável, de Lilyan Berlim, na seção Costuras. Considerando uma abordagem autoral e inédita sobre o conjunto de valores que podem construir outros entendimentos em torno do slow fashion, a autora minimiza a visão simplista e discursiva usada pelo mercado e revalida o slow fashion como um conceito potente sustentado por engajamento ideológico e prático. Na intenção de oferecer uma possibilidade de colaborar na construção do termo no campo, a autora amplia a visão já consolidada, desmistifica as relações de poder e de classe construídas em torno do termo e nos oferece novos caminhos para pensar o slow fashion no contexto local e global.

Boa leitura! 